\title{
Rift Valley fever: current challenges and future prospects
}

This article was published in the following Dove Press journal:

Research and Reports in Tropical Medicine

II March 2016

Number of times this article has been viewed

\section{Yousif E Himeidan}

Vector Control Unit, Africa Technical Research Centre, Vector Health International, Arusha, Tanzania
Correspondence: Yousif E Himeidan Vector Control Unit, Africa Technical Research Centre, Vector Health International,Arusha - Dodoma Road, Arusha, PO Box 15500, Tanzania Email yousif@vectorhealth.com
Abstract: Rift Valley fever (RVF) is a zoonotic, mosquito-borne viral disease that affects human health and causes significant losses in the livestock industry. Recent outbreaks have led to severe human infections with high mortality rates. There are many challenges to applying effective preventive and control measures, including weak infrastructure of health facilities, lack of capacity and support systems for field logistics and communication, access to global expert organizations, and insufficient information on the epidemiological and reservoir status of the RVF virus. The health systems in East African countries are underdeveloped, with gaps in adaptability to new, more accurate and rapid techniques, and well-trained staff that affect their capacity to monitor and evaluate the disease. Surveillance and response systems are inadequate in providing accurate information in a timely manner for decision making to deal with the scope of interrupting the disease transmission by applying mass animal vaccination, and other preventive measures at the early stage of an outbreak. The historical vaccines are unsuitable for use in newborn and gestating livestock, and the recent ones require a booster and annual revaccination. Future live-attenuated RVF vaccines should possess lower safety concerns regardless of the physiologic state of the animal, and provide rapid and long-term immunity after a single dose of vaccination. In the absence of an effective vaccination program, prevention and control measures must be immediately undertaken after an alert is generated. These measures include enforcing and adapting standard protocols for animal trade and movement, extensive vector control, safe disposal of infected animals, and modification of human-animal contact behavior. Directing control efforts on farmers and workers who deal with, handle, or live close to livestock, and focusing on areas with populations at high risk of an epidemic are desirable. Consideration of prevention methods as a first-line strategy against RVF is practical owing to the absence of a human vaccine, particularly under the current high environmental risks and expanding global travel and animal trade. Universal platforms are needed to support coordinated efforts; alert and response operations; exchange of expertise; and disease detection, diagnosis, control, and prevention.

Keywords: RVFV, outbreaks, current challenges, future prospects

\section{Introduction}

Rift Valley fever (RVF) is an important, neglected, zoonotic, mosquito-borne viral disease that causes severe human illness and death, as well as significant economic losses in the livestock industry. The disease is caused by RVF virus (RVFV), an arbovirus of the Bunyaviridae family. ${ }^{1,2}$ The virus is known to infect different animal hosts, particularly sheep, cattle, and goats. ${ }^{2}$ Infection by RVFV usually spreads in animals first via mosquito bites. ${ }^{2}$ From animals, the virus is transmitted to humans through direct contact, such as contact with the raw products or secretions of infected animals. ${ }^{3,4}$ The submit your manuscript | www.dovepress.com

Dovepress

http://dx.doi.org/1 0.2147/RRTM.S63520
Research and Reports in Tropical Medicine 2016:7 I-9

(c) (1) (5) 2016 Himeidan. This work is published and licensed by Dove Medical Press Limited. The full terms of this license are available at https://www.dovepress.com/terms.php cc. ${ }_{\mathrm{BY}} \mathrm{NC}$ and incorporate the Creative Commons Attribution - Non Commercial (unported, $\mathrm{v3.0)}$ License (http://creativecommons.org/licenses/by-nd/3.0/). By accessing the work you hereby accept the Terms. Non-commercial uses of the work are permitted without any further permission from Dove Medical Press Limited, provided the work is properly attributed. For permission for commercial use of this work, please see paragraphs 4.2 and 5 of our Terms (https://www.dovepress.com/terms.php). 
virus can also be transmitted by aerosols from blood and other infected body fluids, and infections are frequent among virologists, veterinarians, and slaughterhouse workers. ${ }^{5,6}$ Though infrequent, vertical transmission also occurs among both humans and animals. ${ }^{7}$ In rare cases, Anopheles, Aedes, and Culex mosquitoes can transmit the virus to humans. ${ }^{8,9}$ Aedes mosquitoes are considered to be the major maintenance host and source of RVFV outbreaks. ${ }^{10-13}$ It has been confirmed that RVFV is carried in Aedes mosquito eggs, which can survive in dried mud for several years. ${ }^{14}$ Transovarial transmission of RVFV depends on certain ecological conditions that enable the virus to survive in water while infected eggs hatch to become adult mosquitoes. ${ }^{15}$ However, these ecological conditions cannot fully explain why RVFV outbreaks do not occur at random but rather show a close association with heavy rainfall, mainly the El Niño-Southern Oscillation, as well as sea surface temperature anomalies in the Indian and Pacific Oceans. ${ }^{16}$ Whereas the role of the Aedes mosquito in outbreak initiation is fundamental, virus amplification and circulation can also occur via Culex and Anopheles mosquitoes. ${ }^{4}$ In East Africa, the complexity of the epidemiological pattern of the disease is owing to the fact that different mosquito species can serve as epidemic/epizootic vectors of RVFV. ${ }^{17}$

Recent RVF outbreaks have been characterized by severe infection and death in humans, with a high case-fatality rate (CFR) of $50 \%$ for the hemorrhagic syndrome form. ${ }^{18}$ Recent East African outbreaks in Tanzania, Kenya, and Somalia caused 478 human deaths in 1998 and 309 in 2007. ${ }^{19-21}$ In Saudi Arabia, the first recorded outbreak occurred in 2000, resulting in 883 human cases with 124 deaths (CFR 14\%) in that country ${ }^{22}$ and 1,328 human cases and 166 deaths in neighboring northwestern Yemen. ${ }^{23-25}$ During the 2007 outbreak in Sudan, 698 cases and 222 deaths were recorded. ${ }^{26}$ It is clear that the epidemiological pattern of recent RVFV outbreaks has changed to resulting in more severe illness and high fatality rates among humans. ${ }^{27-29}$ In addition, the disease can result in negative consequences to the livestock, and other sectors of the economy. For example, the 2006/2007 RVFV outbreak resulted in losses of over 60 million USD, equivalent to the annual value of livestock trade between East African countries. ${ }^{30}$ The 2007 outbreak in Sudan led to bans on livestock exports to Saudi Arabia, which had a massive economic impact on trade between the two countries. ${ }^{31}$

RVFV possesses great potential to spread to new regions, with the disease extending from East Africa (Kenya, Somalia and Tanzania) to Madagascar Island in 1991 ${ }^{32-36}$ and to Saudi Arabia and Yemen on the Arabian Peninsula in
$2000 .{ }^{37}$ This situation calls for collaboration between different regional and governmental health and agricultural sectors, as well as local and international organizations and institutions, to set up practical and integrated approaches so as to mitigate RVFV transmission and to control its spread during outbreaks. It is important to illustrate the main challenges and difficulties that lead to increased human cases and death. These need to be properly addressed and corrective actions should be incorporated into an effective health system for predicting and controlling RVFV. This article aims to bring to the fore information on the challenges experienced in this regard and to describe future prospects for managing the disease.

\section{Opportunities for predicting RVF outbreaks}

RVF has proven capable of emerging in new areas, or reappearing after long periods of dormancy. The reemergence pattern of RVFV in Eastern Africa is associated with the El Niño-Southern Oscillation phenomenon, which causes heavy rainfall during its warm phase. Such excessive rainfall usually causes mosquito vector populations to increase and as a consequence, significantly enlarges reservoirs of the pathogen. It is well documented that all RVF outbreaks reported in Tanzania from 1930 to 2007 were found to occur during, and after El Niño events, ie, between December and June. ${ }^{38}$

The use of satellite imagery and weather and climate forecasting models to develop early warning systems for the prediction of RVF are seen as a sophisticated method to successfully alert national authorities, who can implement key measures for the prevention of impending epidemics. The outbreaks of late 2006 and the first half of 2007 were predicted, for the first time, with acceptable accuracy for the coastal countries of Eastern Africa (Kenya, Somalia, and the United Republic of Tanzania). ${ }^{39,40}$ The disease reemerged in September 2007 in Sudan following excessive rainfall driven by a post-El Niño and unusually warm sea temperatures in the Indian Ocean. ${ }^{40}$ At the same time in 2007 and 2008, the disease also affected countries in Southern Africa (Swaziland and South Africa) and islands in the Indian Ocean (the Comoros, Mayotte, and Madagascar). ${ }^{41-43}$ The forecasting models used, which were based on satellite measurements of elevated sea surface temperatures, elevated rainfall, and satellite-derived normalized vegetation index data available on a continental scale, proved to be efficient in generating early warnings, before the onset of outbreaks. ${ }^{40}$

Using the case of the 2007 RVF outbreak in Sudan as an example, the first early warning alert generated by the model through satellite monitoring was issued in early June 2007.40 
The forecast excessive rainfall took place in July and August 2007 and caused severe flooding in the central states of the country. ${ }^{44}$ The first suspected human RVF cases appeared in the southern areas of Algabalain locality in White Nile State and were reported in September 2007, 3 months later. ${ }^{40}$ The symptom seen among these suspected human cases was hemorrhagic fever, with rapid death. All cases reported during the early part of the outbreak dispersed and did not reach any health facilities. ${ }^{45}$ In general, few or poor health infrastructure facilities are available in these rural areas, a fact that appears to be the main cause for the high fatality rate. Samples from suspected RVF cases must be sent to the National Medical Health Laboratory in Khartoum for diagnostic testing by serological methods, using mainly antigen-capture enzyme-linked immunosorbent assay (ELISA) for confirmation. Serological testing requires time for antibodies against the virus to be produced, and usually depend on cross-reactivity in the susceptible host. Some cases may die before diagnostic testing is complete, particularly if a patient reaches a health facility in late stages of the disease. Routine use of reliable, sensitive, and rapid methods for detection of the virus, such as molecular-based techniques, are critical for an effective surveillance system that acts as a fundamental key to successful prevention and control programs. The lack of efficient surveillance systems in Sudan, as in other countries of East Africa, was the reason behind the late confirmation of the first human index case on 8-14 October, 2007 (Week 41, 2007); ${ }^{40}$ the RVF outbreak came to public attention when the World Health Organization (WHO) joined the Federal Ministry of Health in Sudan on October 24, to investigate a suspected case of hemorrhagic fever in the White Nile State of Central Sudan. Based on the initial results, an RVF outbreak was declared on October 28 , so as to request further assistance with implementation of the key control measures. ${ }^{27}$ In early November when the outbreak reached its peak in humans, an announcement was made regarding RVF outbreak in animals. ${ }^{46}$

Through entomological and epidemiological data in human and livestock populations, it has been confirmed that the recent RVF outbreaks in the Horn of Africa, Sudan, and Southern Africa were predicted using a risk model, with marginal times of 2-4 months. ${ }^{40}$ The overall performance of the model showed that the best reported risk mapping was achieved in East Africa (Kenya, Somalia, and Tanzania) with $65 \%$ of human cases mapped, followed by Sudan with $50 \%$, Madagascar with 23\%, and Southern Africa with 20\%. ${ }^{40}$ The performance of the risk prediction model was linked to a combination of several factors including epidemiological data and surveillance of livestock and human cases, animal movements and migration, and the RVF potential epizootic area mask. ${ }^{40}$ Developing this model was a critical step despite some difficulty in generalizing the model to dissimilar ecological areas as other important factors that had not yet been incorporated into the current model, ie, effects of immunity and human-animal interactions, and effects of control interventions. The model considered only livestock, and Aedes and Culex species as mosquito vectors. Work is currently underway to extend the model to include the spatial distribution of RVFV, vaccination, vector control, livestock movement, and other potential prevention measures with human health implications. ${ }^{47}$

In addition to the previously mentioned efforts, the Food and Agricultural Organization (FAO) of the United Nations and WHO held a joint meeting in September 2008 and issued the following recommendations:

1. Improvement is needed with regard to forecasting models, to be more specific and accurate, and to include potentially major RVF outbreak areas.

2. Models should be developed that are capable of generating an alert 6 months before the onset of an outbreak in animals.

3. RVF risk maps for potential outbreak areas should be used to evaluate RVF outbreaks over time.

4. There should be more involvement of different associated governmental departments, such as meteorological, health, and agricultural agencies in the development of prediction and alert systems. ${ }^{48}$

Compliance with these recommendations is crucial to maximizing the potential of models to provide robust guidance for decision makers at both national and international levels. ${ }^{47}$

\section{Challenges for timely implementation of key prevention and control measures}

From the experiences of recent outbreaks, it has become clear that a large gap exists between model-generated risk warnings and implementation of prevention and control measures. In Sudan, for example, the first early warning alert for the 2007 RVF outbreak was issued in Week 25 (2007) and the outbreak was declared 18 weeks later, after the first index human case was confirmed, during Week 43 (2007). Similar experiences have occurred in other countries. An alert was generated for Southern Africa in early December 2007 and the first human case identified in the country was in February 2008. Similarly, RVF outbreak alerts were generated for Kenya, Somalia, and Tanzania by Week 38 (2006) and the 
first index human case was reported 11 weeks later, during Week 49 (2006) in Tanzania. In Kenya, the index case was also reported 18 weeks later, at the end of January/early February 2007 during Week 4 (2007). The long lead times between generation of an alert and confirmation of the first index case reflect the inefficiency of surveillance and control systems in these countries. ${ }^{40}$

The window of time from alert generation to recognition of the first human case, 2-4 months or more for East Africa (Kenya, Somalia, and Tanzania) and Sudan, is insufficient for effective system communication, efficient response, and timely implementation of appropriate actions to mitigate the disease transmission cycle at an early stage and thereby minimize human infections and deaths. As a result, a cumulative total of 698 cases and 222 deaths were recorded in early January 2008, at the end of the outbreak in Sudan. Because of the lack of a timely response to the alert, the outbreak spread from its origin in White Nile to neighboring states, mainly Gezira and Sennar, where the outbreak had a devastating effect on the local population, yielding an overall CFR of $31.8 \%{ }^{49}$ This outbreak was the first epidemic in Sudan reported among humans and was associated with heavy rainfall and flooding. ${ }^{50}$ If the transmission cycle had been interrupted at its origin by mass animal vaccination, restricted animal movements, and intensive vector control before outbreak onset, the subsequent high number of cases and deaths could likely have been avoided.

The historical use of vaccines based on either the liveattenuated Smithburn virus or on inactivated whole virus was limited to Sub-Saharan Africa. All currently available vaccines are based on the live-attenuated Smithburn strain of the RVF virus. The vaccines based on 103 and 106 mouse brain passage levels produced in cell culture using baby hamster kidney (BHK) cells have been commercialized by Onderstepoort Biological Products (OBP) in South Africa since 1952, and by the Kenya Veterinary Vaccines Production Institute since 1960, respectively; these two vaccines have been widely used in Africa. ${ }^{51} \mathrm{New}$ live-attenuated vaccine candidates such as the MP-12 vaccine, a recombinant RVFV that contains deletions in two of the three genome segments, as well as the clone 13 vaccine, are in advanced stages of testing and development. MP-12 has shown effective immunogenicity in late-gestation sheep and young lambs, however, its margin of safety remains in question - extensive vaccination trials using this vaccine have resulted in abortions and/or severe teratogenicity. ${ }^{52}$ The clone 13 vaccine is registered in South Africa with very good safety and efficacy in cattle and sheep. ${ }^{52}$ The former vaccine is unsuitable for use in newborn and gestating livestock, and the latter requires a booster and annual revaccination, which is logistically near impossible in the region. Additional new vaccines are expected to reach the market in the coming decade. It is generally agreed that novel vaccines should be safe regardless of the physiologic state of the animal, affordable, and should provide rapid and long-term immunity after a single dose of vaccine. ${ }^{53}$ To effectively control the transmission of RVFV by vaccination, animals in high risk areas must be vaccinated early, within the window of susceptibility to infection (ie, the first 4-6 weeks after a risk warning has been generated for the area), for the vaccinated animal population to develop sufficient immunity against the virus. ${ }^{54}$ In the absence of an effective vaccination program, intensive vector control should target the primary infected mosquito populations before virus amplification and circulation takes place among animals, to significantly diminish virus reservoirs and the number of animal and human cases. Aedes mosquito populations are vital to maintaining RVFV and initiating infection; nevertheless, effective vector control programs should be designed to target all mosquito vector species, particularly those of the Culicinae subfamily, owing to their critical role in amplification of the virus during epidemics. ${ }^{55}$ However, timely implementation of effective vaccination and vector control programs requires establishment of efficient and reliable surveillance and communication systems.

In discussions regarding the RVFV outbreaks in Sudan and East Africa, the FAO and WHO concluded that despite the generation of warnings, implementation of preventive measures and key control strategies in this context were difficult. ${ }^{48}$ The challenges faced can be attributed to one or more of the following factors:

1. Gaps in the domains of established standard operating procedures for alerts and control responses as well as the monitoring and evaluation of RVF.

2. Lack of procedures for local and international operations and communications, ie, field information management systems.

3. Absence of well-organized and trained national leaders and teams for vector surveillance, virus reservoir investigation, and outbreak response. Protocols for rapid deployment of international experts also do not exist.

4. Lack of field support systems including logistics capacity support packages.

5. Lack of established international and regional partners and a network of experts to support and provide direct assistance to affected countries. 
6. Difficulty in sourcing funds for vaccines; mobile laboratory equipment, supplies, and reagents; and rapid molecular and serological assays for the detection of different viruses and strains. These fundamental materials and tools are unavailable locally and procedures are lacking for health care agencies to affect their provision in a timely, efficient, and cost-effective manner.

7. Challenges with regard to transportation to remote and inaccessible field locations for sample and data collection, which subsequently led to insufficient information regarding clinical and epidemiological disease status.

These gaps in the core capacities of health systems, including logistics and other fundamental functions of outbreak response programs, must be addressed so as to adequately respond to outbreak alerts and implement necessary control measures in a timely fashion.

\section{Challenges to controlling risk factors and surveillance of RVF virus}

During an RVF outbreak, it is generally accepted that direct contact with animals and animal products are the main risk factors. ${ }^{45}$ During a 2010 outbreak in Sudan, an increase of abortions was noticed in ewes, and the disease was first recognized in people with histories of close contact with aborted fetal material. ${ }^{56}$ Consumption or handling of raw animal material infected with RVFV, including contact with an aborted animal fetus or working as a herdsman, has been shown to be the primary risk factors for severe RVF infection in Kenya and South Africa. ${ }^{40,57}$ A study in Sudan also concluded that most affected farmers had frequent close contact with infected animals, including in the farmers' living quarters. ${ }^{4,58}$

Avoiding direct or indirect contact with animals during an RVF outbreak ${ }^{2}$ is therefore one of the most important challenges to be faced, particularly in rural areas. It is very important in such cases to increase consciousness about the risk factors of RVF infection and encourage farmers and others at risk, to use protective means to prevent unsafe contact with infected animals or animal materials during an outbreak. WHO recommends that public health awareness strategies should focus on reducing unsafe human-animal contact associated with animal husbandry and slaughter practices. Such information should indicate specific recommended personal protective equipment (PPE) and clothing to be worn, particularly when handling sick animals. Appropriate use of PPE, such as the N95 mask (after passing a fit test), is more effective than a face shield or surgical mask, which do not offer appropriate protection. Despite delivery of detailed information, these personal protective tools may not be used effectively or might not be present and available in time for use by persons at risk of infection. This highlights the difficulty in protecting local populations once RVFV is actively emerging and spreading. In such cases, transmission arising from contact with animal products, such as the consumption of fresh blood, raw milk, or animal tissue, must be urgently controlled. In regions with the greatest potential risk, all animals should be vaccinated and animal materials handled carefully and systematically, such as by cooking meat very well before eating. Public awareness programs to deliver information about such protective measures should also address ways to prevent mosquito bites, a source for transmission of the virus from an infected animal. The use of long-lasting insecticidal nets is important in providing community protection against mosquito vectors. Personal means of protection such as by using insect repellents; wearing treated clothing, long-sleeved shirts, and trousers; and avoiding evening and early-morning outdoor exposure are also effective. Despite the fact that most RVFV patients recover without long-term sequelae, up to $10 \%$ of the patients may develop full or partial blindness. It is therefore critical to address the above challenges during an outbreak, to successfully reduce human risks for infection. Unfortunately, communication of such public health messages in the East African countries and Sudan is often ineffective owing to political pressure to prevent regulation or other measures seen as harmful to the livestock industry and trade. This situation may lead to delays in taking important RVFV control measures, which can result in increased human disease and deaths.

Restricted animal movement during an outbreak inside the affected country is another important challenge. Animal trade and movement remains a serious risk factor for introducing the virus into neighboring areas and even across borders, resulting in the spread of disease to neighboring countries. This is often the case among East African countries. For example, multiple RVFV strains grouped into Kenya-1 or Kenya-2 sublineages that defined the Eastern Africa outbreak in 2006-2008 were found during the 2007 and 2010 outbreaks in Sudan, suggesting multiple introductions of RVFV from East Africa. ${ }^{56,59}$ The movement of animals to market locations is responsible for the spread of the 2007 outbreak from White Nile to the states of Gezira, Sennar, Khartoum, and Kassala in that country. Movement of an infected animal represents the most important risk factor for expanding the geographical distribution of RVFV, not only inside one country as in $\operatorname{Sudan}^{60}$ but also to other countries, 
for example, to Saudi Arabia during the Hajj season. It has been established that the first outbreak in Asia during the year 2000 was introduced from East Africa by importation of infected animals, ${ }^{21,22,61,62}$ similar to the suggested route of introduction of RVFV into Egypt from Sudan in 1977. ${ }^{63}$ The same virus strain that caused the 1997-1998 outbreaks in East Africa was confirmed to have caused the Saudi Arabia outbreak. ${ }^{64}$ Saudi Arabia is the country, in this region, with the most importation of live animals from East Africa and Sudan. According to Saudi regulations, all imported ruminants must be vaccinated in the exporting countries before shipment. However, a recent study indicated that the rules covering importation and quarantine of live animals are not followed effectively. ${ }^{65}$ Among animals imported into Saudi Arabia from Sudan, 21.21\% tested positive for anti-RVFV IgG antibodies; among those from Somalia, 6.11\% were seropositive. The study also showed that no animal had an available vaccination history. ${ }^{65}$ This calls for reinforcement and strict follow-up of established regulations to ensure that the spread of RVFV can be well controlled.

The emergence of RVF should lead to animal export bans owing to inclusion of the disease on the World Organisation for Animal Health (OIE) notifiable disease list A, and international regulations or regional protocols for required conditions must be instated for livestock trade. However, the solution to the problem is most likely a political one rather than establishment of regulations and protocols. For example, announcing an outbreak in East Africa and Sudan has great potential to result in food insecurity owing to an indirect negative impact on pastoralists' socioeconomic life. This is supported by the fact that more than $40 \%$ ( 70 million) of people in Kenya, Somalia, and Tanzania suffer from chronic food insecurity. ${ }^{66}$ The governments of these regions therefore exercise great caution when deciding whether to announce an RVFV outbreak. According to the OIE prevention requirements, other countries should not import any vulnerable animal from a country considered to have been infected by RVF within the last 3 years. However, countries in the region vulnerable to the disease have nonexistent or very weak animal movement control systems in most areas.

Veterinary-based surveillance systems and animal trade regulations should be reinforced so that early detection and preventive action can be undertaken. Veterinary surveillance is a critical factor for the current rules of the global economy and international regulations owing to having the responsibility for collecting, analyzing, and delivering epidemiological data and launching the required preventive actions. Epidemiological surveillance systems are fundamental to identifying appropriate processes and techniques for assessment of such veterinary services. The quality of the information delivered by surveillance and accuracy of the methods involved in a system could be used as indicators when assessing and validating such animal health systems. It is clear that even in countries that are considered underdeveloped, veterinary systems and services should play a fundamental role in providing information in a transparent, accurate, and timely manner for decision making at regional and international levels. Clear guiding policies, effective organizational structures, effective communication and information systems, adaptability to new and more accurate techniques, proper allocation of acceptable budgets, well-trained staff, and rigorous intensive research are considered to be indispensable requirements for building reliable veterinary surveillance and service systems. These essential elements are nearly nonexistent or very ineffective in most countries that represent possible sources for an RVF outbreak.

\section{Future prospects}

Currently, RVFV is limited to Africa and the Arabian Peninsula, but the virus has demonstrated clear characteristics that might place nations outside its current borders at risk. ${ }^{20,67}$ Infection by the virus often results in significant loss of livestock and severe illness and high fatality rates among humans; however, there are presently no licensed, commercially available human vaccines. Future live-attenuated RVF vaccines should possess lower safety concerns than the current vaccines. ${ }^{68}$ In the absence of the development of a safe and effective vaccine, adequate standardized detection and diagnostic procedures and reliable surveillance systems are crucial under the current situation of high environmental risks. The gradual introduction of RVFV to new regions and continents would severely damage and adversely affect human and animal health, as well as the livestock and other economic sectors. ${ }^{69}$ The probability of RVFV emergence in new areas is likely to increase because the geographical range of the virus has been shown to have extended in recent years. It has been proposed that a single infected animal entering a naïve country is sufficient to induce a severe outbreak before RVFV would be detected. ${ }^{70}$ Unless mass vaccination becomes widely available for use in East African livestock, RVFV will likely continue to be a real threat to human and animal health. Mass vaccination may become critical for significant growth in international trade. There is an increased potential for the transfer of the sporadic pathogen from one continent to another, either 
through vector transport or the trade of ruminants or infected wild animals during an epizootic in endemic countries, particularly when viremia levels are high. ${ }^{71}$ This becomes of greater importance in view of the fact that dependence of the RVFV-vector interaction on environmental conditions indicates that projected climate change could possibly extend the geographical distribution and climatic conditions suitable for virus transmission. With the potential for greater risks under ongoing climate change, increased global travel, and expanding regional and international trade, priority should be given to prevention measures as the first lines of defense against this disease..$^{71}$

Early detection and containment of RVF at its geographical origin should be a global goal, to interrupt transmission and eliminate or eradicate this disease. The current passive case surveillance systems in regions where this virus commonly originates are incapable of early detection and rapid reporting of infections. Universal platforms are urgently needed to support current surveillance systems and meet needs with respect to the provision of vaccines, antiviral agents, and trained staff and to establishing critical diagnostic tests and procedures. Reliable and validated modeling and analytic tools are essential to support informed policy and decision making by industry and government. Modeling may be extended to evaluating the current control strategies, approximating the potential spatial distribution of the disease, and estimating the economic costs of possible introduction of RVFV into new territories. ${ }^{47}$ Prevention and control measures that should be undertaken immediately after an alert is generated include enforcing and adapting standard protocols for animal trade and movement, extensive vector control that targets both adult and larval stages, mass vaccination of livestock if applicable, safe discarding of infected animals, and modification of human-animal contact behavior via knowledge transfer by education and outreach. Focusing control efforts on farmers and workers who deal with, handle, or live near livestock would be highly cost-effective. Interruption of the transmission cycle without mass vaccination at outbreak onset is likely to be impossible even with extensive effective vector control aim to keep mosquito vector populations at minimum levels. In this manner, infected female mosquitoes can be eliminated and amplification of RVFV among viremic host animals could be significantly reduced. Shrinking potential virus reservoirs in animal and vectors at the start of an outbreak requires mass vaccination and intensive, targeted vector control programs. Minimizing unsafe human-animal contact in the early stages of an outbreak is also necessary and requires dissemination of simple but clear information throughout areas where an outbreak may occur and adversely effect the local population. Components that are critical for future management of this disease include a review of current research, assessment of current control approaches and strategies, as well as effective training of scientists, field teams, and early responders. ${ }^{47}$

\section{Disclosure}

The author declares that there is no conflict of interest in this work.

\section{References}

1. Daubney R, Hudson JR. Rift Valley fever. Lancet. 1932;1:611-612.

2. Rift Valley fever. Fact sheet $N^{\circ} 207$. World Health Organization. Revised May 2010. Retrieved 29 November 2015. Available from: http://www. who.int/mediacentre/factsheets/fs207/en/. Accessed February 10, 2016.

3. Acha P, Szyfres B. Zoonoses and Communicable Diseases Common to Man and Animals. 2nd ed, Scientific Publication No 503. Washington, DC: Pan American Health Organization/World Health Organization Scientific Publication; 1987.

4. Seufi AM, Galal FH. Role of Culex and Anopheles mosquito species as potential vectors of rift valley fever virus in Sudan outbreak, 2007. BMC Infect Dis. 2010;10:65.

5. Turkistany AH, Mohamed AG, Al-Hamdan N. Seroprevalence of Rift Valley fever among slaughterhouse personnel in Makkah during Hajj 1419h (1999). J Family Community Med. 2001;8(3):53-57.

6. Antonis, AF, Kortekaas J, Kant J, Vloet RP, Vogel-Brink A, Stockhofe N, Moormann RJ. Vertical transmission of rift valley fever virus without detectable maternal viremia. Vector Borne Zoonotic Dis. 2013;13(8):601-606.

7. Easterday BC, McGavran MH, Rooney JR, Murphy LC. The pathogenesis of Rift Valley fever in lambs. Am J Vet Res. 1962;23:470-479.

8. Laughlin LW, Meegan JM, Strausbaugh LJ, Morens DM, Watten RH. Epidemic Rift Valley fever in Egypt: observations of the spectrum of human illness. Trans R Soc Trop Med Hyg. 1979;73(6):630-633.

9. Linthicum KJ, Davies FG, Kairo A, Bailey, CL. Rift Valley fever virus (family Bunyviridae, genus Phlebovirus). Isolations from diptera collected during an inter-epizootic period in Kenya. J Hyg (Lond). 1985;95(1):197-209.

10. Davies FG. Observation on the epidemiology of Rift Valley fever in Kenya. J Hyg (Lond). 1975;75(2):219-230.

11. Linthicum KJ, Anyamba A, Tucker CJ, Kelley PW, Myers MF, Peters CJ. Climate and satellite indicators to forecast Rift Valley fever epidemics in Kenya. Science. 1999;285(5426):397-400.

12. O'Malley CM. Aedes vexans (Meigen): an old foe. In: Proceedings of New Jersey Mosquito Control Association. 1990:90-95.

13. Crabtree MB, Kent Crockett RJ, Bird BH, Nichol ST, Erickson BR, Biggerstaff BJ, et al. Infection and Transmission of Rift Valley Fever Viruses Lacking the NSs and/or NSm Genes in Mosquitoes: Potential Role for NSm in Mosquito Infection. PLoS Negl Trop Dis. 2012;6(5):e1639.

14. Davies FG, Linthicum KJ, James AD. Rainfall and epizootic Rift Valley fever. Bull World Health Organ. 1985;63(5):941-943.

15. Sang R, Kioko E, Lutomiah J, et al. Rift Valley fever virus epidemic in Kenya, 2006/2007: the entomologic investigations. Am J Trop Med Hyg. 2010;83(2):28-37.

16. Kahlon SS, Peters CJ, Leduc J, et al. Severe Rift Valley fever may present with a characteristic clinical syndrome. Am J Trop Med Hyg. 2010;82(3):371-375.

17. Kebede S, Duales S, Yokouide A, Alemu W. Trends of major disease outbreaks in the African region, 2003-2007. East Afr J Public Health. 2010;7(1):20-29. 
18. Clements AC, Pfeiffer DU, Martin V, Otte MJ. A Rift Valley fever atlas for Africa. Prev Vet Med. 2007;82(Suppl 1-2):72-82.

19. Mohamed M, Mosha F, Mghamba J, et al. Epidemiologic and clinical aspects of a Rift Valley fever outbreak in humans in Tanzania, 2007. Am J TropMed Hyg. 2010;83(2):22-27.

20. World Health Organization. Rift Valley fever fact sheet. Wkly Epidemiol Rec. 2008;83(2):17-22.

21. World Health Organization. Outbreaks of Rift Valley fever in Kenya, Somalia, and United Republic of Tanzania, December 2006-April 2007. Wkly Epidemiol Rec. 2007;82(20):169-178.

22. Centers for Disease Control and Prevention (CDC, 2000a). Update: outbreak of Rift Valley fever - Saudi Arabia, August-November 2000. Morb Mortal Wkly Rep. 2000;49(43):982-985.

23. Elfadil AA, Hasab-Allah KA, Dafa-Allah OM. Factors associated with Rift Valley fever in south-west Saudi Arabia. Rev Sci Tech. 2006:25(3):1137-1145.

24. Balkhy HH, Memish ZA. Rift Valley valley fever: an uninvited zoonosis in the Arabian peninsula. Int J Antimicrob Agents. 2003;21(2):153-157.

25. Saudi Ministry of Health. Department of Preventive Medicine and Field Epidemiology Training Program. Rift Valley fever outbreak, Saudi Arabia. Saudi Epidemiol Bull. 2000;8:1-8.

26. Centers for Disease Control and Prevention (CDC). Rift Valley fever outbreak-Kenya, November 2006-January 2007. MMWR Morb Mortal Wkly Rep. 2007;56(4):73-76.

27. World Health Organization. Report update 4: Rift Valley fever in Sudan. WHO Report; 2007 [updated December 21, 2007]. Available from http://www.who.int/csr/don/2007_12_21/en/. Accessed February 10, 2016.

28. Centers for Disease Control and Prevention (CDC). Outbreaks of Rift Valley fever in Kenya, Somalia and United Republic of Tanzania, December 2006-April 2007. Wkly Epidemiol Rec. 2007;82(20): 169-178.

29. Adam AA, Karsany MS, Adam I. Manifestations of severe Rift Valley fever in Sudan. Int J Infect Dis. 2010;14(2):e179-e180.

30. Little PD. Hidden value on the hoof: cross-border livestock trade in Eastern Africa. Common market for Eastern and Southern Africa comprehensive African agriculture development program, policy brief number 2; 2009. Available from: http://www.nepad-caadp.net/pdf/COMESA $\% 20$ CAADP\%20Policy\%20Brief\%202\%20Cross\%20Border\%20Livestock\%20Trade\%20(2).pdf. Accessed February 10, 2016.

31. Hassan OA, Ahlm C, Evander M. A need for one health approach lessons learned from outbreaks of Rift Valley fever in Saudi Arabia and Sudan. Infect Ecol Epidemiol. 2014;4:10.3402/iee.v4.20710.

32. Morvan J, Fontenille D, Saluzzo JF, Coulanges P. Possible Rift Valley fever outbreak in man and cattle in Madagascar. Trans $R$ Soc Trop Med Hyg. 1991a;85(1):108.

33. Morvan J, Saluzzo JF, Fontenille D, Rollin PE, Coulanges P. Rift Valley fever on the east coast of Madagascar. Res Virol. 1991;142(6):475-482.

34. Morvan J, Lesbordes JL, Rollin PE, Mouden JC, Roux J. First fatal human case of Rift Valley fever in Madagascar. Trans $R$ Soc Trop Med Hyg. 1992;86(3):320.

35. Morvan J, Rollin PE, Laventure S, Rakotoarivony I, Roux J. Rift Valley fever epizootic in the central highlands of Madagascar. Res Virol. 1992b;143(6):407-415.

36. Carroll SA, Reynes JM, Khristova ML, Andriamandimby SF, Rollin PE, Nichol ST. Genetic evidence for Rift Valley fever outbreaks in Madagascar resulting from virus introductions from the East African mainland rather than enzootic maintenance. J Virol. 2011;85(13):6162-6167.

37. Ahmad K. More deaths from Rift Valley fever in Saudi Arabia and Yemen. Lancet. 2000;356(9239):1422.

38. Sindato C, Karimuribo ED, Pfeiffer DU, et al. Spatial and temporal pattern of Rift Valley fever outbreaks in Tanzania; 1930 to 2007. PLoS One. 2014;9(2):e88897.

39. Anyamba A, Chretien JP, Small J, et al. Prediction of a Rift Valley fever outbreak. Proc Natl Acad Sci USA. 2009;106:955-959.
40. Anyamba A, Linthicum KJ, Small J, et al. Prediction, assessment of the Rift Valley fever activity in East and Southern Africa 2006-2008 and possible vector control strategies. Am J Trop Med Hyg. 2010; 83(Suppl 2):43-51.

41. Sissoko D, Giry C, Gabrie P, et al. Rift Valley fever, Mayotte, 2007-2008. Emerg Infect Dis. 2009;15(4):568-570.

42. Andriamandimby SF, Randrianarivo-Solofoniaina AE, Jeanmaire EM, et al. Rift Valley fever during rainy seasons, Madagascar, 2008 and 2009. Emerg Infect Dis. 2010;16(6):963-970.

43. Roger M, Girard S, Faharoudine A, et al. Rift Valley fever in ruminants, Republic of Comoros, 2009. Emerg Infect Dis. 2011;17(7): 1319-1320.

44. Moszynski P. Flooding worsens in Sudan. BMJ. 2007;335(7612):175.

45. El Imam M, El Sabiq M, Omran M, et al. Acute renal failure associated with the Rift Valley fever: a single center study. Saudi J Kidney Dis Transpl. 2009;20(6):1047-1052.

46. Garang GD. A press release on Rift Valley Fever disease in Sudan 10/11/2007. Khartoum: Federal Ministry of Animal Resources and Fisheries; 2007. Available from: https://flutrackers.com/forum/forum/ emerging-diseases-other-health-threats-alphabetical-i-thru-z/rift-valleyfever/26455-rift-valley-fever-outbreak-in-sudan-abates-who. Accessed February 10, 2016.

47. Hartley DM, Rinderknecht JL, Nipp TL, Clarke NP, Snowder GD. National Center for Foreign Animal and Zoonotic Disease Defense Advisory Group on Rift Valley Fever. Potential effects of Rift Valley fever in the United States. Emerg Infect Dis. 2011;17(8):e1.

48. World Health Organization. Rift Valley Fever Outbreaks Forecasting Models. Joint FAO - WHO Expert's Consultation, 29th September1st October 2008, Rome, Italy. 2009. Available from: http://www.who. int/csr/resources/publications/WHO_HSE_GAR_BDP_2009_2c.pdf. Accessed February 10, 2016.

49. World Health Organization. Report update 5: Rift Valley fever in Sudan. WHO Report; 2008 [updated January 22, 2008]. Available from: http://www.who.int/csr/don/2008_01_22/en/. Accessed December 29, 2015.

50. Hassan OA, Ahlm C, Sang R, Evander M. The 2007 Rift Valley fever outbreak in Sudan. PLoS Negl Trop Dis. 2011;5(9):e1229.

51. Lubroth J, Rweyemamu MM, Viljoen G, Diallo A, Dungu B, Amanfu W. Veterinary vaccines and their use in developing countries. Rev Sci Tech. 2007;26(1):179-201.

52. Hunter P, Erasmus BJ, Vorster JH. Teratogenicity of a mutagenised Rift Valley fever virus (MVP 12) in sheep. Onderstepoort J Vet Res. 2002;69(1):95-98.

53. Kortekaas J, Zingeser J, de Leeuw P, de La Rocque S, Unger H, Moormann RJ. Rift Valley fever vaccine development, progress and constraints. Emerg Infect Dis. 2011;17(9):e1.

54. Ikegami T, Makino S. Rift valley fever vaccines. Vaccine. 2009;27 (Suppl 4):D69-D72.

55. Mweya CN, Holst N, Mboera LE, Kimera SI. Simulation modelling of population dynamics of mosquito vectors for Rift Valley fever virus in a disease epidemic setting. PLoS One. 2014;9(9):e108430.

56. Aradaib IE, Erickson BR, Elageb RM, et al. Rift Valley fever, Sudan, 2007 and 2010. Emerg Infect Dis. 2013;19(2):246-253.

57. Woods CW, Karpati AM, Grein T, et al. World Health Organization Hemorrhagic Fever Task Force. An outbreak of rift valley fever in Northeastern Kenya, 1997-1998. Emerg Infect Dis. 2002;8(2):138-144.

58. Hassanain AM, Noureldien W, Karsany MS, Saeed el NS, Aradaib IE, Adam I. Rift Valley fever among febrile patients at New Halfa hospital, eastern Sudan. Virol J. 2010;7:97.

59. Bird BH, Githinji JW, Macharia JM, et al. Multiple virus lineages sharing recent common ancestry were associated with a large Rift Valley fever outbreak among livestock in Kenya during 2006-2007. J Virol. 2008;82(22):11152-11166.

60. Himeidan YE, Kweka EJ, Mahgoub MM, El Rayah el A, Ouma JO. Recent outbreaks of rift valley fever in East Africa and the Middle East. Front Public Health. 2014;2:169. 
61. Centers for Disease Control and Prevention (CDC, 2000b). Outbreak of Rift Valley fever - Saudi Arabia, August-October, 2000. Morb Mortal Wkly Rep. 2000;49(40):905-908.

62. Miller BR, Godsey MS, Crabtee MB, et al. Isolation and genetic characterization of Rift Valley fever virus from Aedes vexans arabiensis, Kingdom of Saudi Arabia. Emerg Infect Dis. 2002;8(12):1492-1494.

63. Gad AM, Feinsod FM, Allam IH, et al. A possible route for the introduction of Rift Valley fever virus into Egypt during 1977. Am J Trop Med Hyg. 1986;89(5):233-236.

64. Shoemaker T, Boulianne C, Vincent MJ, et al. Genetic analysis of viruses associated with emergence of Rift Valley fever in Saudi Arabia and Yemen, 2000-2001. Emerg Infect Dis. 2002;8(12):1415-1420.

65. Mohamed AM, Ashshi AM, Asghar AH, Abd El-Rahim IH, El-Shemi AG, Zafar T. Seroepidemiological survey on Rift Valley fever among small ruminants and their close human contacts in Makkah, Saudi Arabia, in 2011. Rev Sci Tech. 2014;33(3):903-915.

66. Food and Agriculture Organization of the United Nations (FAO). Serious commitment to fight hunger in the Horn of Africa. Strategy to end hunger in the Horn of Africa, 2001. Available from: http://www. fao.org/english/newsroom/highlights/2001/010705-e.htm. Accessed February 10, 2016.
67. European Food Safety Authority (EFSA). Opinion of the Scientific Panel on Animal Health and Welfare on a request from the commission related to "The risk of a Rift Valley fever incursion and its persistence within the community". EFSA J. 2005;238:1-128.

68. Lihoradova O, Ikegami T. Countermeasure development for Rift Valley fever: deletion, modification or targeting of major virulence factor NSs. Future Virol. 2014;9(1):27-39.

69. Mandell RB, Flick R. Rift Valley fever virus: a real bioterror threat J Bioterr Biodef. 2011;2:108.

70. Balenghien T, Cardinale E, Chevalier V, et al. Towards a better understanding of Rift Valley fever epidemiology in the south-west of the Indian Ocean. Vet Res. 2013;44:78.

71. Rolin AI, Berrang-Ford L, Kulkarni MA. The risk of Rift Valley fever virus introduction and establishment in the United States and European Union. Emerg Microbes Infect. 2013;2(12):e81.
Research and Reports in Tropical Medicine

\section{Publish your work in this journal}

Research and Reports in Tropical Medicine is an international, peerreviewed, open access journal publishing original research, case reports, editorials, reviews and commentaries on all areas of tropical medicine, including: Diseases and medicine in tropical regions; Entomology; Epidemiology; Health economics issues; Infectious disease; Laboratory

\section{Dovepress}

science and new technology in tropical medicine; Parasitology; Public health medicine/health care policy in tropical regions; and Microbiology. The manuscript management system is completely online and includes a very quick and fair peer-review system. Visit http://www.dovepress. com/testimonials.php to read real quotes from published authors. 